\title{
Effects of pH on the Kinetics of Methyl Tertiary Butyl Ether Degradation by Oxidation Process $\left(\mathrm{H}_{2} \mathrm{O}_{2} /\right.$ Nano Zero-Valent Iron/Ultrasonic)
}

\author{
Mohammad Reza Samaei ${ }^{1, *} ;$ Hoshang Maleknia ${ }^{1}$; Abooalfazl Azhdarpoor ${ }^{1}$ \\ ${ }^{1}$ Department of Environmental Health Engineering, School of Health, Shiraz University of Medical Sciences, Shiraz, IR Iran \\ *Corresponding author: Mohammad Reza Samaei, Department of Environmental Health Engineering, School of Health, Shiraz University of Medical Sciences, Shiraz, IR Iran. Tel: \\ +98-9177320737, E-mail: mrsamaei@sums.ac.ir
}

Received: May 26, 2015; Revised: June 20, 2015; Accepted: June 27, 2015

\begin{abstract}
Background: In advanced oxidation processes, $\mathrm{pH}$ has a significant effect on the removal efficiency of organic compounds. This study examined the effect of $\mathrm{pH}$ changes on the removal efficiency and kinetics of methyl tertiary butyl ether (MTBE) concentration in aquatic environment.

Objectives: The primary objective of this study was to evaluate the effect of $\mathrm{pH}$ changes on removal kinetics of the mentioned compound, using $\mathrm{H}_{2} \mathrm{O}_{2} / \mathrm{nZVI}$ (nano zero-valent iron)/ultrasonic process, and its impact on the reaction rate.

Materials and Methods: In order to create the right conditions for oxidation, first of all iron nanoparticles combined with $\mathrm{H}_{2} \mathrm{O}_{2}$ oxidizer were synthesized, and then they were subjected to ultrasound waves and used in MTBE oxidation. In MTBE removal via $\mathrm{H}_{2} \mathrm{O}_{2}$ $\mathrm{nZVI} /$ Ultrasonic process, the effects of some parameters such as contact time ( 2 to 60 minutes), concentration of hydrogen peroxide ( 5 to $20 \mathrm{~mL} / \mathrm{L}$ ), concentrations of nZVI ( 0.15 to $0.45 \mathrm{~g} / \mathrm{L}$ ), MTBE concentrations ( 50 to $750 \mathrm{mg} / \mathrm{L}$ ), and pH (2 to 9) were investigated. MTBE concentration analysis was performed using gas chromatography (GC).

Results: According to this study, the best removal efficiency of $50 \mathrm{mg} / \mathrm{L} \mathrm{MTBE}$ concentration in $89.56 \%$ under oxidation condition occurred when $\mathrm{H}_{2} \mathrm{O}_{2}$ level equals to $10 \mathrm{~mL} / \mathrm{L}, \mathrm{nZVI}$ is $0.25 \mathrm{~g} / \mathrm{L}$ at pH 3.5. The results showed that the increase or decrease of $\mathrm{pH}$ from 3.5 results in a loss of oxidation efficiency as well as reduction in the amount of $\mathrm{k}_{\mathrm{ap}}$. In addition, the logarithmic changes curve of MTBE concentration showed that MTBE oxidation in $\mathrm{H}_{2} \mathrm{O}_{2} / \mathrm{nZVI} /$ ultrasonic method follows pseudo first order reactions.

Conclusions: Changes of $\mathrm{pH}$ could remarkably affect the efficiency and oxidation rate of MTBE. In particular, the amount of $\mathrm{k}_{\mathrm{ap}}$ in terms of oxidation declines substantially by moving away from the optimum $\mathrm{pH}$ range. In this study, $\mathrm{pH} 3.5$ was considered as the optimal $\mathrm{pH}$ in $\mathrm{H}_{2} \mathrm{O}_{2} / \mathrm{nZVI} /$ ultrasonic oxidation process, with the elimination of about $89.56 \%$ of the high MTBE concentration. In general, we can say that by adjusting $\mathrm{pH}$ in this range, the rate and efficiency of MTBE oxidation can be enhanced in $\mathrm{H}_{2} \mathrm{O}_{2} / \mathrm{nZVI} /$ ultrasonic method.

Keywords: MTBE; kinetics; pH
\end{abstract}

\section{Background}

In recent years, research on advanced contaminant treatment processes in aquatic environments has become more common, in particular, advanced oxidation processes are important because of their efficiency (1). Studies show that advanced oxidation processes that are highly reactive in aquatic environment (based on the formation of free radicals) have high ability in the destruction of high strength wastes under optimal operation $(2,3)$. Performance of advanced oxidation processes are highly dependent on the oxidation conditions such as reaction time, $\mathrm{pH}$ range of the environment, type and concentration of oxidizing and oxidized compounds, and use of chemical and physical factors generating hydroxyl radicals in the process (4, 5 ). The results of the studies in this area indicate that under identical conditions, the oxidation resistance of different chemical compounds differs from each other and depends on the nature and structure of chemical pollutants (2). Kinetics of chemical oxidation reactions of pollutants can be important in achieving optimal conditions and determining the oxidation reaction of chemicals with respect to time and different operating conditions (6).

In the past decade, zero-valent iron (ZVI) is considered as an effective agent for treating organic compounds in aquatic environments (7). However, studies have shown that ZVI reactivity significantly increases by reducing the size at the nanoscale (nZVI). The reactivity of iron nanoparticles is 500 to 1000 times higher than iron powder (8), because iron nanoparticles (nZVI) become corroded in acidic conditions, and generate iron ions. These ions in the presence of hydrogen peroxide cause oxidation of contaminants through Fenton process (3).

Removal mechanism of contaminants using ZVI is the direct transfer of electrons from ZVI to contaminant compounds that result in conversion of pollutants to non-toxic or less toxic compounds. On the other hand, ZVI can oxidize and decompose contaminants in the

Copyright @ 2015, Ahvaz Jundishapur University of Medical Sciences. This is an open-access article distributed under the terms of the Creative Commons Attribution-NonCommercial 4.0 International License (http://creativecommons.org/licenses/by-nc/4.0/) which permits copy and redistribute the material just in noncommercial usages, provided the original work is properly cited. 
presence of soluble oxygen as the result of transferring of two electrons to $\mathrm{O}_{2}$ molecule and producing $\mathrm{H}_{2} \mathrm{O}_{2}$. Hydrogen peroxide formed during this process can transfer two other electrons from ZVI to produce water molecule. In addition, $\mathrm{H}_{2} \mathrm{O}_{2}$ and $\mathrm{Fe}^{2+}$ synthesis (fenton process) can lead to the formation of hydroxyl radicals $\left(\mathrm{OH}^{0}\right)$ as the most important factor of organic compounds oxidation (Equations 1-3)

$$
\begin{aligned}
& \mathrm{Fe}^{\mathrm{O}}+\mathrm{O}_{2}+2 \mathrm{H}+\rightarrow \mathrm{Fe}^{2+}+\mathrm{H}_{2} \mathrm{O}_{2} \\
& \mathrm{Fe}^{\mathrm{O}}+\mathrm{H}_{2} \mathrm{O}_{2}+2 \mathrm{H}+\rightarrow \mathrm{Fe}^{2+}+2 \mathrm{H}_{2} \mathrm{O} \\
& \mathrm{Fe}^{2+}+\mathrm{H}_{2} \mathrm{O}_{2} \rightarrow \mathrm{Fe}^{3+}+\mathrm{OH}^{0}+\mathrm{OH}^{-}
\end{aligned}
$$

High standard reduction potential of ZVI makes the restoration work to be carried out in an appropriate manner. During this process, iron oxide (Equation 4) and alkyl aldehydes are restoring (Equation 5). The process take place in a very favorable thermodynamic condition (Equation 6) (9).

$$
\begin{array}{r}
\mathrm{Fe}^{0} \rightarrow \mathrm{Fe}^{2+}+2 e^{-} \\
\mathrm{RX}+H^{+} \rightarrow \mathrm{RH}+X^{-} \\
\mathrm{Fe}^{0}+\mathrm{RX}+H+\rightarrow \mathrm{Fe}^{2+}+\mathrm{RH}+X^{-}
\end{array}
$$

In addition, ZVI produces hydrogen gas and hydroxide ion as a result of reaction with water, which leads to an increase in $\mathrm{pH}$ during water oxidation process (Equation 7) (10).

$$
\mathrm{Fe}^{\mathrm{O}}+2 \mathrm{H}_{2} \mathrm{O} \rightarrow \mathrm{Fe}^{2+} 2 \mathrm{OH}^{-}+\mathrm{H}_{2}
$$

Ultrasonic waves accelerate chemical or biological processes in water and wastewater treatment operations. When the pressure increases, the tensile strength of the fluid in low pressure or diluted areas creates tiny vapor bubbles, known as cavitation, which creates a strong mechanical and sonochemical effects, which convert suspension particles and large molecules in the liquid, into smaller particles $(11,12)$.

Combining ultrasound and Fenton (sono-Fenton) is one of the most widely used advanced oxidation processes in the treatment of organic pollutants from wastewater. In Fenton process, the produced $\mathrm{Fe}^{2+}$ ions react with hydrogen peroxide and produce hydroxyl radicals (reaction 2). In this reaction, $\mathrm{OH}^{0}$ attacks organic molecules and destroys their structure during the process of radical oxidation, hydrogen abstraction, electron transfer, and radical integration. These processes are presented in chemical equations 8 to 11 , respectively $(13,14)$.

$$
R+\mathrm{OH}^{0} \rightarrow \mathrm{ROH}
$$

$$
\begin{array}{r}
R+\mathrm{OH}^{0} \rightarrow R^{0}+\mathrm{H}_{2} \mathrm{O} \\
R^{n}+\mathrm{OH}^{0} \rightarrow R^{n-1}+\mathrm{OH}^{0} \\
\mathrm{OH}^{0}+\mathrm{OH}^{0} \rightarrow \mathrm{H}_{2} \mathrm{O}_{2}
\end{array}
$$

Analysis of MTBE kinetics is highly dependent on the concentration of hydroxyl radicals produced in the oxidation process, the latter of which depends on the type of chemical oxidation process and the nature of the oxidizing agent. Contact time, MTBE initial concentration, and temperature are other factors involved in MTBE decomposition kinetics (15). The oxidation process system is also effective on removal kinetics. According to the study by Boonrattanakij et al. on the kinetics of 6, 2-dimethyl aniline in batch and continuous systems, the batch system shows better performance compared to the continuous system in similar working conditions (16). In the study by Hwang et al. on MTBE oxidation via Fenton-like method, at initial concentration of $11 \mathrm{mM} \mathrm{MTBE}, 6 \mathrm{mM} \mathrm{H}_{2} \mathrm{O}_{2}$ and 5 $\mathrm{mM} \mathrm{Fe}^{2+}$, after 90 minutes only $45 \%$ of the initial MTBE concentration was removed. These differences in the effect of oxidation time can be attributed to the use of nZVI and its role in accelerating the oxidation process (17).

\section{Objectives}

Given the environmental importance of MTBE and the impact of various factors on the performance of MTBE oxidation process using advanced oxidation (including environmental $\mathrm{pH}$ as the most important factor influencing the process based on free radical formation), the primary objective of this study was to evaluate the effect of $\mathrm{pH}$ changes on the removal kinetics of this compound using $\mathrm{H}_{2} \mathrm{O}_{2} / \mathrm{nZVI} /$ ultrasonic process and its impact on the reaction rates.

\section{Materials and Methods}

\subsection{Chemical Compounds}

Methyl tertiary butyl ether $\left(\left(\mathrm{CH}_{3}\right)_{3} \mathrm{COCH}_{3}\right)$ compound with the purity of $99.9 \%$ and hydrogen peroxide $\left(\mathrm{H}_{2} \mathrm{O}_{2}\right)$ with a purity of $30 \%$, n-Pentane, toluene, hydrochloric acid, and sodium hydroxide with laboratory purity were purchased from Merk Company.

\subsection{Nanoparticles Synthesis}

Iron nanoparticles used in this study were synthesized 
using sodium borohydride. During the process of synthesis, nanoparticles were synthesized by adding sodium borohydride solution $(0.1 \mathrm{M})$ to ferric chloride solution $\left(\mathrm{FeCl}_{3}\right.$ $.6 \mathrm{H}_{2} \mathrm{O}$ ) at room temperature. Ferric chloride solution was prepared by dissolving $0.5406 \mathrm{~g}$ of solid $\mathrm{FeCl}_{3} \cdot 6 \mathrm{H}_{2} \mathrm{O}$ in ethanol water solution with a volume ratio of $4 / 1$ (4 parts ethanol to one part water). To prepare a solution of sodium borohydride, sodium hydroxide 0.1 was used. After preparing the solutions, sodium borohydride solution was added and dropped (one drop every 2 seconds) in severe mixing conditions (in vacuum) to ferric chloride solution. With the addition of the first few drops of sodium borohydride solution, black colored solid particles (iron particles) quickly appeared. This condition lasted about 30 minutes. The vacuum filtration method was used for the separation of the liquid phase from black iron nanoparticles. The isolated nanoparticles were washed 3 times with $25 \mathrm{~mL}$ ethanol to remove all water. This can be considered as the most important phase of NZVI synthesis, because prevents rapid oxidation of NZVI. Eventually, the washed nanoparticles were put in the oven overnight and dried at $50^{\circ} \mathrm{C}$. In order to prevent oxidation in air, nanoparticles were stored in ethanol solution $(8,18)$. To determine the properties of produced iron nanoparticles, TEM electron microscope was used (Figure 1).

\subsection{Methodology}

The reactor used in the process was Plax glass double layered with 1 L capacity (Figure 2), which was placed in the Elmasonic-S60h model ultrasonic device with a constant frequency of $60 \mathrm{~Hz}$ and $500 \mathrm{~kW}$ power. First, $1 \mathrm{~L}$ of co-distilled water was poured into the reactor. Then, based on the variables and research objectives, one factor was considered as variable, and others kept as constants. To adjust the temperature $\left(30^{\circ} \mathrm{C}\right)$, cooling water in the reactor chamber was used. After sampling, the samples were placed in a centrifuge device at 4000 rpm for 5 minutes. All samples were collected in glass containers with Teflon cap and kept at $4^{\circ} \mathrm{C}$. To adjust the $\mathrm{pH}, 1 \mathrm{~N}$ hydrochloric acid, and $1 \mathrm{~N}$ sodium hydroxide were used. N-Pentane was used as an extraction agent and toluene as an internal standard. In MTBE removal via $\mathrm{H}_{2} \mathrm{O}_{2} / \mathrm{nZVI} /$ ultrasonic process, the effects of some parameters such as contact time (2 to 60 minutes), concentration of hydrogen peroxide ( 5 to $20 \mathrm{~mL} / \mathrm{L}$ ), concentrations of nZVI ( 0.15 to $0.45 \mathrm{~g} / \mathrm{L})$, MTBE concentrations (50 to $750 \mathrm{mg} / \mathrm{L}$ ), and $\mathrm{pH}$ (2 to 9 ) were investigated. The samples were measured using GC-FID device to evaluate the residual amount of MTBE. Chromatographic conditions were as follows: detector temperature: $250^{\circ} \mathrm{C}$, temperature at injection point: $180^{\circ} \mathrm{C}$, column temperature: $32^{\circ} \mathrm{C}$, column temperature increase gradient: $6^{\circ} \mathrm{C} / \mathrm{min}$, column high temperature: $115^{\circ} \mathrm{C}$, and initial time: 2 minutes. Standard curves for MTBE concentration was drawn, and the remaining concentration was calculated using the curve.

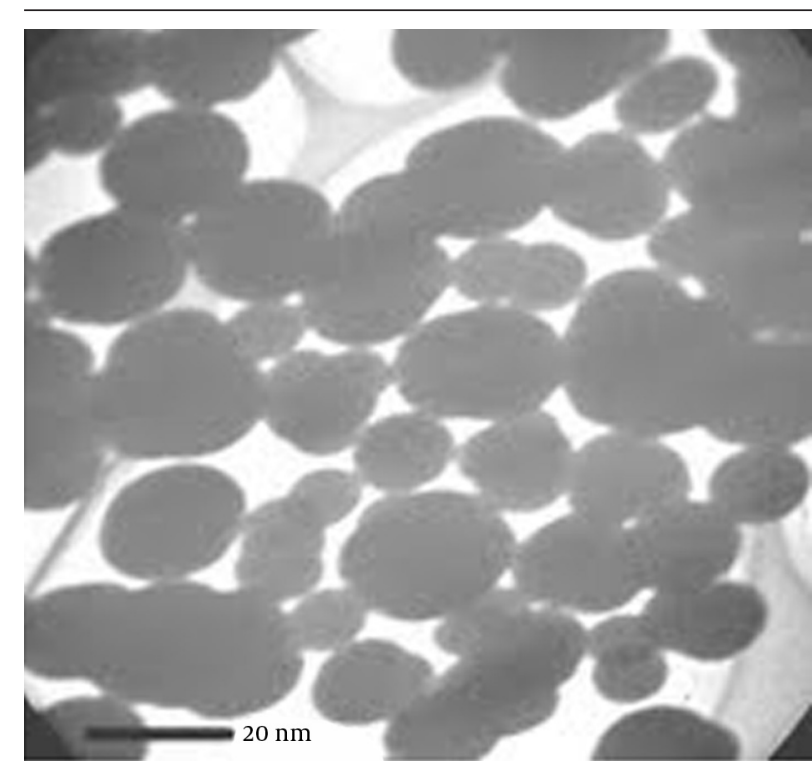

Figure 1. TEM Image of Synthesized nZVI

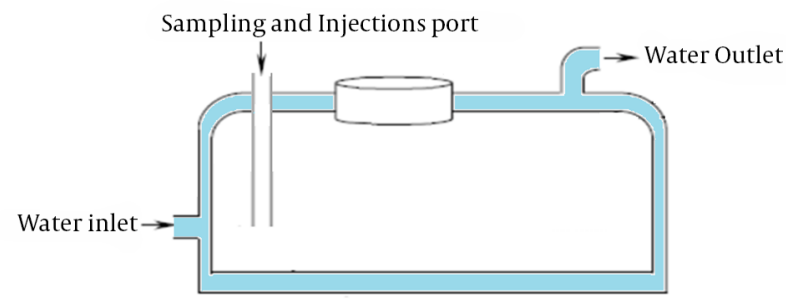

Figure 2. The Oxidation Reactor

\section{Results}

In this study, MTBE oxidation was studied using $\mathrm{H}_{2} \mathrm{O}_{2}$ $\mathrm{nZVI} /$ Ultrasonic process at different $\mathrm{pH}$ levels. For this study, concentrations of MTBE, $\mathrm{H}_{2} \mathrm{O}_{2}$, and NZVI were fixed at $500 \mathrm{mg} / \mathrm{L}, 10 \mathrm{~mL} / \mathrm{L}$, and $0.25 \mathrm{~g} / \mathrm{L}$, respectively. Each experiment was repeated twice and the data shown in the charts are based on average data for each stage of the test. The $\mathrm{pH}$ values in this study were $2,3.5,5,7$, and 9 .

\subsection{Effect of pH Changes on MTBE Removal Effi- ciency}

In oxidation conditions of $10 \mathrm{~mL} / \mathrm{L} \mathrm{H}_{2} \mathrm{O}_{2}, 0.25 \mathrm{~g} / \mathrm{L} \mathrm{nZVI}$ , and $50 \mathrm{mg} / \mathrm{L}$ MTBE, removal efficiency at $\mathrm{pH}=3.5$ was about $89.56 \%$, and in the same conditions, at $\mathrm{pH}=9$ it reduced to $44.14 \%$. According to the results, the oxidation under acidic conditions was better compared to neutral and alkaline conditions. However, the acidity level of the oxidation environment was also important. So that the performance at $\mathrm{pH}=2$ was lower than $\mathrm{pH}=3.5$, and was equal to $76.93 \%$ (Figure 3). 
4.2. Effect of pH Changes on the Rate of MTBE Elimination in Unit of Time

Study of the effects of time on $\mathrm{H}_{2} \mathrm{O}_{2} / \mathrm{nZVI} /$ ultrasonic oxidation method showed that MTBE concentration undergoes significant changes quickly and in the early minutes

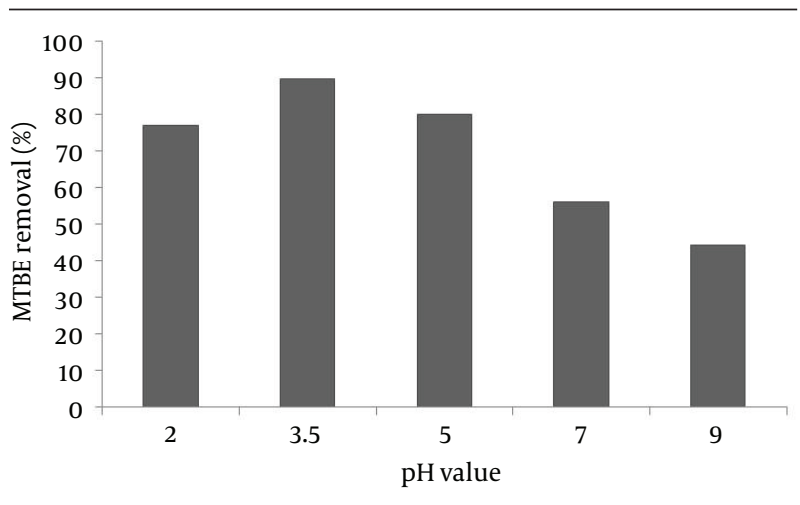

Figure 3. The Effect of pH Changes on MTBE Removal Efficiency in $10 \mathrm{~mL} / \mathrm{L}$ $\mathrm{H}_{2} \mathrm{O}_{2}, 0.25 \mathrm{~g} / \mathrm{L} \mathrm{nZVI}, 50 \mathrm{mg} / \mathrm{L}$ MTBE Condition

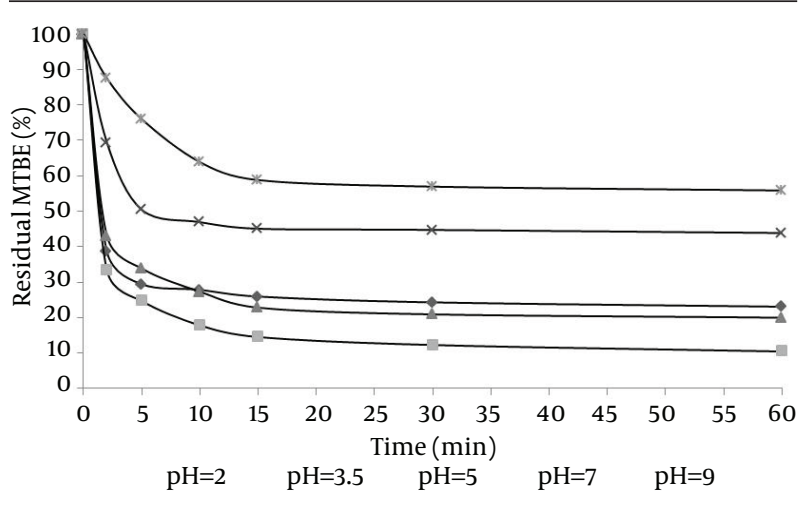

Figure 4. Remaining MTBE Percentage, 60 Minutes After Oxidation at 10 $\mathrm{mL} / \mathrm{L} \mathrm{H}_{2} \mathrm{O}_{2}, 0.25 \mathrm{~g} / \mathrm{L} \mathrm{nZVI}$, and $500 \mathrm{mg} / \mathrm{L}$ MTBE of oxidation. According to the results, oxidation rate was very high in the first minutes after the start of the process (especially the first 10 minutes). The results of oxidation in $\mathrm{H}_{2} \mathrm{O}_{2}$ concentration $=10 \mathrm{~mL} / \mathrm{L}, \mathrm{nZVI}=0.25 \mathrm{~g} / \mathrm{L}, \mathrm{MTBE}=$ $500 \mathrm{mg} / \mathrm{L}$, and in $\mathrm{pH}$ values of 2,3.5, 5, 7, and 9 are shown in Figure 4. The results showed that the percentage of remaining MTBE, 60 minutes after the beginning of oxidation and in $\mathrm{pH}$ values of $2,3.5,5,7$, and 9 were $23.07 \%$, $10.44 \%, 19.99 \%, 43.88$, and $56.86 \%$, respectively.

\subsection{MTBE Oxidation Rate Values in the Test Opti- mal Conditions}

To determine the effect of $\mathrm{pH}$ changes on MTBE decomposition constant rate $\left(\mathrm{k}_{\mathrm{ap}}\right)$, oxidation tests with the initial concentration of $\mathrm{H}_{2} \mathrm{O}_{2}, \mathrm{nZVI}$, and MTBE as $10 \mathrm{~mL} / \mathrm{L}$, $0.25 \mathrm{~g} / \mathrm{L}$, and $500 \mathrm{mg} / \mathrm{L}$ were performed. In addition, the levels of $\mathrm{k}\left(\mathrm{min}^{-1}\right)$ were calculated through the following kinetic equation and the results are shown in Table 1.

$$
\begin{aligned}
\ln \frac{c_{t}}{c_{0}} & =-\mathrm{kt} \\
k & =\frac{1}{t} \ln \frac{c_{0}}{c_{t}}
\end{aligned}
$$

Where:

$\mathrm{C}_{0}$ : initial MTBE concentration at time $\mathrm{t}=0(\mathrm{mg} / \mathrm{L})$

$\mathrm{C}_{\mathrm{t}}$ : MTBE Concentration at time $\mathrm{t}$

$\mathrm{k}$ : constant kinetic rate of first-order reactions $\left(\mathrm{min}^{-1}\right)$

t: reaction time ( $\mathrm{min}$ )

According to Table 1 and Figure 5, the MTBE decomposition constant rate $\left(\mathrm{k}_{\mathrm{ap}}\right)$ increases over time, and at any time it depends on the amount of oxidation and the optimum condition of the oxidation environment. According to Table 1 , the highest value obtained for $\mathrm{k}_{\mathrm{ap}}$ was

\begin{tabular}{|c|c|c|c|c|c|c|c|}
\hline \multirow{2}{*}{$\begin{array}{l}\text { Effect of } \mathrm{pH} \text { Changes on Initial } \\
\text { Logarithmic Mtbe Concentration } \\
\text { Changes at The Unit of Time }\end{array}$} & \multicolumn{7}{|c|}{ Time, min } \\
\hline & $\mathbf{0}$ & 2 & 5 & 10 & 15 & 30 & 60 \\
\hline $\operatorname{Ln}(\mathrm{MTBE} / \mathrm{MTBE}), \mathrm{pH}=\mathbf{2}$ & 0 & 0.951141 & 1.222476276 & 1.277978218 & 1.348998576 & 1.414282398 & 1.466637114 \\
\hline $\mathbf{K}_{\mathbf{a p}}$ & 0 & 0.475571 & 0.244495 & 0.127798 & 0.089933 & 0.047143 & 0.024444 \\
\hline $\operatorname{Ln}(\mathrm{MTBE} / \mathrm{MTBE}), \mathrm{pH}=3.5$ & 0 & 1.098412 & 1.398771883 & 1.724848764 & 1.928266714 & 2.097198263 & 2.259525604 \\
\hline $\mathbf{K}_{\mathrm{ap}}$ & 0 & 1.004836 & 1.144212 & 1.34967 & 1.429406 & 1.482871 & 1.540617 \\
\hline Ln (MTBE/MTBE), pH = 5 & 0 & 0.841879 & 1.082640519 & 1.297185186 & 1.477532842 & 1.564464547 & 1.609938037 \\
\hline $\mathbf{K}_{\mathrm{ap}}$ & 0 & 0.766451 & 0.773994 & 0.752057 & 0.766249 & 0.745978 & 0.712512 \\
\hline Ln (MTBE/MTBE), $\mathbf{p H}=7$ & 0 & 0.365716 & 0.684187439 & 0.75608698 & 0.796509694 & 0.80430223 & 0.823711551 \\
\hline $\mathbf{K}_{\mathrm{ap}}$ & 0 & 0.434404 & 0.631962 & 0.582867 & 0.539081 & 0.514107 & 0.511642 \\
\hline Ln (MTBE/MTBE), pH = 9 & 0 & 0.133303 & 0.274568433 & 0.448476999 & 0.530688253 & 0.562820919 & 0.582321625 \\
\hline$K_{\mathbf{a p}}$ & 0 & 0.364499 & 0.401306 & 0.593155 & 0.666267 & 0.699763 & 0.706948 \\
\hline
\end{tabular}
achieved at $\mathrm{pH}$ 3.5. 


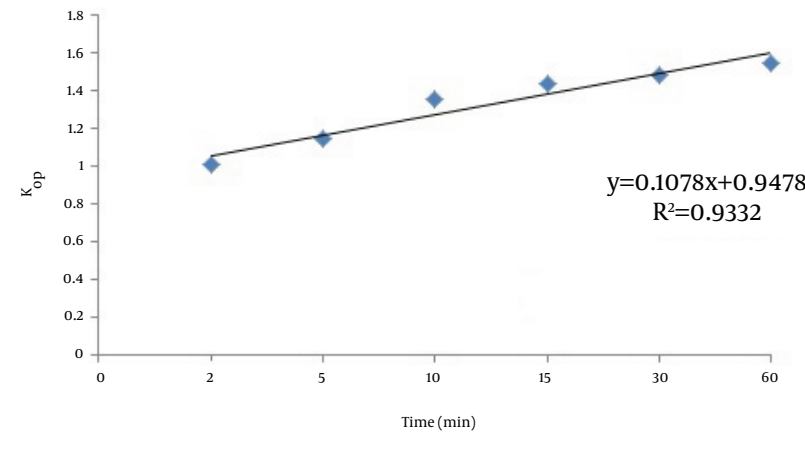

Figure 5. Changes in the Rate of MTBE Decomposition per Unit of Time $\left(\mathrm{k}_{\mathrm{ap}}\right)$ in pH Equal to 3.5 and in Conditions of $10 \mathrm{~mL} / \mathrm{L} \mathrm{H}_{2} \mathrm{O}_{2}, 0.25 \mathrm{~g} / \mathrm{L} \mathrm{nZVI}$, and $500 \mathrm{mg} / \mathrm{L}$ MTBE

\section{Discussion}

The effect of $\mathrm{pH}$ changes on oxidation kinetics and removal of MTBE composition using $\mathrm{H}_{2} \mathrm{O}_{2} / \mathrm{nZVI} /$ ultrasonic oxidation process was studied. In previous studies in the field of fenton process, it was shown that low $\mathrm{pH}$ is highly effective on oxidation process performance $(19,20)$.

The results of the current study show that in acidic $\mathrm{pH}$ condition, removal efficiency is higher than neutral or alkaline conditions. During the oxidation process, $\mathrm{pH}$ undergoes changes through the time, and because of the production of $\mathrm{H}^{+}$ion in test environment (Equation 14 ), it decreases gradually. These $\mathrm{pH}$ changes causes the MTBE removal changes curve to be different in various $\mathrm{pH}$ ranges (21).

Our results on the effect of $\mathrm{pH}$ are consistent with the studies of Burbano et al. In their study, which was on the effect of $\mathrm{pH}$ on MTBE removal in Fenton process, different values of $\mathrm{pH}$ from acidic to neutral was studied, and eventually it became clear that the highest MTBE removal efficiency occurred in the $\mathrm{pH}$ range of 3 to 3.5 (6). Darban et al. studied the reduction of MTBE concentration in water using Fenton method and determined the changes resulting from reaction conditions in producing byproducts. The results showed that MTBE removal efficiency was about $99.99 \%$ at $\mathrm{pH}=3$ (22). Bergendahl et al. carried out Fenton oxidation process using ZVI, and found that $99 \%$ of MTBE at acidic $\mathrm{pH}$ was degraded at $\mathrm{H}_{2} \mathrm{O}_{2}$ : MTBE optimum ratio of 220:1(23).

The high efficiency of oxidation under acidic conditions might be due to the high level of surface oxidation of nanoparticles in acidic conditions; $\mathrm{Fe}^{2+}$ ion concentration increases rapidly in the environment and provides the conditions for greater amounts of MTBE oxidation in a short period of time. In these situations, generating ultrasonic waves in the fluid greatly helps higher concentration of $\mathrm{Fe}^{2+}$. Also, due to Fenton chemistry, by increasing $\mathrm{pH}$, various types of iron are deposited as sediment in the form of $\mathrm{Fe}(\mathrm{OH})_{3}$, causing $\mathrm{H}_{2} \mathrm{O}_{2}$ to break down into $\mathrm{O}_{2}$. On the other hand, by reducing $\mathrm{pH}$ under strongly acidic condition, Fe (III) turns into Fe (II). Both of these conditions lead to reduction in concentration of the oxidizing agents (24).

$$
\mathrm{H}_{2} \mathrm{O}_{2}+\mathrm{Fe}^{3+} \rightarrow \mathrm{H}^{+}+\mathrm{FeOOH}^{2+}
$$

According to the results of this study, the highest removed concentration of this compound is in the first 15 minutes. After this time, the removal efficiency shows little change. The results indicate that due to high speed and capacity of hydroxyl radicals in MTBE oxidation, the optimal required time for oxidation of the compound is relatively low.

Kinetic study of the MTBE concentration at unit of time, show that MTBE oxidation somewhat follows the first-order oxidation reactions. Kinetic constant of MTBE concentration changes per unit of time $\left(\mathrm{k}_{\mathrm{ap}}\right)$ and shows partial increase during oxidation process. The results also show that under optimum conditions in terms of $\mathrm{pH}$, the value of $\mathrm{k}_{\mathrm{ap}}$ is higher than other $\mathrm{pH}$ values, and lower level of $\mathrm{k}_{\mathrm{ap}}$ in high $\mathrm{pH}$ is obtained, which is due to remarkable decline in hydroxyl radicals as well as insoluble iron oxide deposits in alkaline $\mathrm{pH}$.

In this study, the role of $\mathrm{pH}$ (acidic, neutral, and alkaline) on MTBE oxidation kinetics using $\mathrm{H}_{2} \mathrm{O}_{2} / \mathrm{nZVI} / \mathrm{ul}$ trasonic advanced oxidation method was investigated. The results showed that $\mathrm{pH}$ could remarkably affect the efficiency and oxidation rate of MTBE. Under identical conditions, the amount of $\mathrm{k}_{\mathrm{ap}}$ in terms of oxidation declines substantially by moving away from the optimum $\mathrm{pH}$ range. In this study, $\mathrm{pH}=3.5$ is considered as the optimal $\mathrm{pH}$ in $\mathrm{H}_{2} \mathrm{O}_{2} / \mathrm{nZVI} /$ ultrasonic oxidation process, with the elimination of about $89.56 \%$ of the high MTBE concentration. Generally, by adjusting $\mathrm{pH}$ in this range, the rate and efficiency of MTBE oxidation can be enhanced in $\mathrm{H}_{2} \mathrm{O}_{2} /$ nZVI/Ultrasonic method.

\section{Acknowledgements}

This article was extracted from the masters' thesis by Hoshang Maleknia with project No.: 93-7019 at Shiraz university of medical sciences. The authors gratefully acknowledge the financial and technical support provided by Shiraz university of medical sciences, Iran.

\section{Authors' Contributions}

Mohammad Reza Samaei, Hoshang Maleknia, Abooalfazl Azhdarpoor equally participated in the design and conduct of the study; collection, management, and analysis of the data; or and preparation, review, and approval of the manuscript.

\section{Funding/Support}

This study was financially and technically supported by Shiraz university of medical sciences, Iran. 


\section{References}

1. Bremner DH, Molina R, Martínez F, Melero JA, Segura Y. Degradation of phenolic aqueous solutions by high frequency sonoFenton systems (US-Fe2O3/SBA-15-H2O2). Appl Catalysis B Environ. 2009;90(3-4):380-8.

2. Azizi E, Ghayebzadeh M, Beikmohammadi M, Sharafi K, Pirsaheb M. Oxidation of aniline with photo-Fenton advanced oxidation process from aqueous solutions in batch reactor. Tech JEngin Applied Sci. 2015;5(2):12-6.

3. Xu L, Wang J. A heterogeneous Fenton-like system with nanoparticulate zero-valent iron for removal of 4-chloro-3-methyl phenol. J Hazard Mater. 2011;186(1):256-64.

4. Xu XR, Zhao ZY, Li XY, Gu JD. Chemical oxidative degradation of methyl tert-butyl ether in aqueous solution by Fenton's reagent. Chemosphere. 2004;55(1):73-9.

5. Zhou H, Shen Y, Lv P, Wang J, Li P. Degradation pathway and kinetics of 1-alkyl-3-methylimidazolium bromides oxidation in an ultrasonic nanoscale zero-valent iron/hydrogen peroxide system.J Hazard Mater. 2015;284:241-52.

6. Burbano AA, Dionysiou DD, Suidan MT, Richardson TL. Oxidation kinetics and effect of $\mathrm{pH}$ on the degradation of MTBE with Fenton reagent. Water Res. 2005;39(1):107-18.

7. Zha S, Cheng Y, Gao Y, Chen Z, Megharaj M, Naidu R. Nanoscale zero-valent iron as a catalyst for heterogeneous Fenton oxidation of amoxicillin. Chem Engin J. 2014;255:141-8.

8. Rahmani AR, Ghafari HR,, Samadi MT, Zarabi M. Synthesis of Zero Valent Iron Nanoparticles (NZVI) and its Efficiency in Arsenic Removal from Aqueous Solutions. Water Wastewater. 2011;1:35-41.

9. Eglal MM. Nanofer Zero-Valent Iron Nanoparticles: Surface Morphology, Structure and Reactivity with Contaminants, in Department of Building, Civil and Environmental Engineering, Concordia University.Canada: Concordia University; 2014.

10. Janda V, Vasek P, Bizova J, Belohlav Z. Kinetic models for volatile chlorinated hydrocarbons removal by zero-valent iron. Chemosphere. 2004;54(7):917-25.

11. the use of ultrasound technology in wastewater treatment. In: Raeesi Oskouei SM, Ayati B editors. . the Sixth National Conference of Environmental Engineering. 2012 Tehran. Faculty of Environment, Tehran University:.

12. Chen D. Applications of ultrasound in water and wastewater treatment. In: Sharma SK, Mudhoo A editors. Handbook on application of ultrasound, sonochemistry for sustainability.. Florida: Boca Raton: CRC Press, Taylor \& Francis Group; 2012

13. Taha MR, Ibrahim AH. Characterization of nano zero-valent iron (nZVI) and its application in sono-Fenton process to remove COD in palm oil mill effluent.J Environ Chem Engin. 2014;2(1):1-8.

14. Rosenfeldt EJ, Linden KG. Degradation of endocrine disrupting chemicals bisphenol A, ethinyl estradiol, and estradiol during UV photolysis and advanced oxidation processes. Environ Sci Technol. 2004;38(20):5476-83.

15. Sun JH, Sun SP, Fan MH, Guo HQ, Qiao LP, Sun RX. A kinetic study on the degradation of p-nitroaniline by Fenton oxidation process. J Hazard Mater. 2007;148(1-2):172-7.

16. Boonrattanakij N, Lu MC, Anotai J. Kinetics and mechanism of 2,6-dimethyl-aniline degradation by hydroxyl radicals. J Hazard Mater. 2009;172(2-3):952-7.

17. Hwang S, Huling SG, Ko S. Fenton-like degradation of MTBE Effects of iron counter anion and radical scavengers. Chemosphere. 2010;78(5):563-8.

18. Yuvakkumar R, Elango V, Rajendrana V, Kannan N. Preparation and characterization of zero valent iron Nanoparticles. Digest J Nanomaterials Biostructures. 2011;6(4):1771-6.

19. Safarzadeh-Amiri A, Bolton JR, Cater SR. The use of iron in advanced oxidation processes. J Adv Oxid Technol. 1996;1:18-26.

20. Moon BH, Park YB, Park KH. Fenton oxidation of Orange II by pre-reduction using nanoscale zero-valent iron. Desalination. 2011;268(1-3):249-52.

21. Eslami A, Nasseri S, Yadollahi B, Mesdaghinia A, Vaezi F, Nabizadeh R. Removal of methyl tert-butyl ether (MTBE) from contaminated water by photocatalytic process. Iran Jof Public Health. 2009;38(2):18-26.

22. Darban AK, Shahmansouri A, Ganjidost H. Fenton remediation of methyl tertiary butyl ether (MTBE) and effects of reaction conditions on the byproducts formed. WaterWastewater. 2009;56:43-50.

23. Bergendahl JA, Thies TP. Fenton's oxidation of MTBE with zerovalent iron. Water Res. 2004;38(2):327-34.

24. Kusic H, Loncaric Bozic A, Koprivanac N. Fenton type processes for minimization of organic content in coloured wastewaters: Part I: Processes optimization. Dyes Pigments. 2007;74(2):380-7. 